\title{
Trophic ecology of an abundant predator and its relationship with fisheries
}

\author{
Adam Barnett ${ }^{1,2,3, *}$ Jonah L. Yick $^{4}$, Kátya G Abrantes ${ }^{2}$, Cynthia A. Awruch $^{5,6}$ \\ ${ }^{1}$ School of Life and Environmental Sciences, Deakin University, 221 Burwood Highway, Burwood, Victoria 3125, Australia \\ ${ }^{2}$ Centre for Tropical Water \& Aquatic Ecosystem Research (TropWATER), Estuary and Tidal Wetland Ecosystems Research Group, \\ School of Marine and Tropical Biology, James Cook University, Townsville, Queensland 4811, Australia \\ ${ }^{3}$ OceansIQ, PO Box 200, Clifton Beach, Cairns, Queensland 4879, Australia \\ ${ }^{4}$ Inland Fisheries Service, PO Box 575, New Norfolk, Tasmania 7140, Australia \\ ${ }^{5}$ Centro Nacional Patagónico (CENPAT_CONICET) Boulevard Brown S/N, 9120 Puerto Madryn, Chubut, Argentina \\ ${ }^{6}$ School of Zoology, University of Tasmania, Private Bag 5, Hobart, Tasmania 7001, Australia
}

\begin{abstract}
Trophic studies are key components in animal ecology and fisheries research. Although stomach samples are often obtained from fisheries, diet studies that consider the influence of fisheries on dietary results are still lacking. Here, the diet of the draughtboard shark Cephaloscyllium laticeps, an abundant mesopredator in Tasmanian waters, was investigated. Stomach samples were obtained from gillnet and craypot fisheries sourced from 4 regions: central (100\% gillnet), east coast (63\% gillnet, $37 \%$ craypot), northwest (100\% gillnet), and southwest Tasmania (100\% craypot). Overall, C. laticeps consumed the same prey types in all regions, but the importance of some prey varied significantly between regions. Generalized linear models showed that region was the main factor affecting prey abundance in the diet. Fishing method had some influence on the abundance of some prey (crabs, octopus, and other molluscs (gastropods and bivalves)), but the effect of fishing method on pot-related species such as Jasus edwardsii (lobster) and octopus was not as prevalent as expected. The common occurrence of $C$. laticeps as a bycatch species and its high consumption of targeted fishery species (lobsters and octopus) indicates that $C$. laticeps has a strong interaction with the fisheries. Therefore, the relationship between these fishery species and $C$. laticeps should be considered in food web studies in Tasmanian waters.
\end{abstract}

KEY WORDS: Shark - Niche separation · Predator-prey relationships · Cephaloscyllium laticeps · Food web $\cdot$ Diet $\cdot$ Fisheries influence

\section{INTRODUCTION}

There is growing recognition of the important roles played by predators in regulating ecosystems and sustaining biodiversity (Heithaus et al. 2008, Ritchie \& Johnson 2009, Estes et al. 2011). However, the functional role of predators cannot be fully appreciated without establishing where the different species fit in food webs and understanding interspecies relationships (e.g. predator-prey, competitive, or resource-sharing relationships) within a given system. As, at its most basic level, the ecological role of a species is defined by its position in the food web, the initial step in studying the importance of a predator on food web and ecosystem dynamics is to identify its dietary composition. This is generally done using gut content analysis. When using gut content analysis, other factors, such as fishing method used, the use of baits, or a predator's relationship with fishery species, may affect dietary results (e.g. Ibáñez et al. 2008), and should be taken into account. However, the influence of factors such as fishing method and fisheries influences on trophic studies is often overlooked. 
The influence of fisheries on marine predators' trophic ecology can be via competition for available resources (Lucifora et al. 2009, Okes et al. 2009, Pichegru et al. 2009), by affecting the spatial scale at which predators forage (Pichegru et al. 2010) or the prey that they target (Gonzalez-Zevallos \& Yorio 2006, Okes et al. 2009). Predators may also feed from fisheries by taking prey from fishing gear (Lunneryd et al. 2003, Varjopuro 2011) or targeting discards (Hill \& Wassenberg 1990, Olaso et al. 1998, Gonzalez-Zevallos \& Yorio 2006, Okes et al. 2009). The interactions of fisheries with seabirds and marine mammals are probably the most commonly studied examples of predators' trophic ecology being influenced by fisheries (e.g. Lunneryd et al. 2003, Okes et al. 2009). However, detailed investigations of the influence of fisheries on the diet of other marine predators such as teleosts and elasmobranchs are lacking. Few studies have considered or at least commented on how fisheries affect shark trophic ecology (Olaso et al. 1998, Simpfendorfer et al. 2001, Koen Alonso et al. 2002) or on how catch methods influence dietary data obtained from stomach samples (Simpfendorfer et al. 2001, Bethea et al. 2004, Baremore et al. 2008). For example, 37.5\% of tiger sharks Galeocerdo cuvier caught on longlines had everted stomachs, meaning that a high percentage of samples were lost to the analyses (Simpfendorfer et al. 2001); angel sharks Squatina dumeril have been shown to feed on prey while they are caught in trawl nets (Baremore et al. 2008), and sevengill sharks Notorynchus cepedianus also feed on prey caught by longlines (Barnett et al. 2010a).

The draughtboard shark Cephaloscyllium laticeps is endemic to temperate Australia and is the most common catshark along the southern Australia coastline, where it is mainly found inshore or on the continental shelf, down to at least $60 \mathrm{~m}$ (Last \& Stevens 2009, Awruch et al. 2012). It grows to a maximum size of $1500 \mathrm{~mm}$, but is rarely seen over $1000 \mathrm{~mm}$ (Last \& Stevens 2009). The high abundance and relatively large size of $C$. laticeps suggests that this species is a key mesopredator in coastal waters, and may share resources with other abundant small- to mid-sized shark species, such as the gummy shark Mustelus antarcticus and the white-spotted dogfish Squalus acanthias (Barnett \& Semmens 2012, Yick et al. 2012). C. laticeps form a significant bycatch component of southeastern Australian fisheries, where they are taken in rock lobster traps (craypots), demersal trawls, longlines, and gillnets (Frusher \& Gibson 1998, Walker et al. 2005, Gardner et al. 2011). Some fishermen consider C. laticeps a nuisance and fear that they affect the catch rates of the southern rock lobster Jasus edwardsii. Apart from the direct effect of predation, it has been alleged that the presence of sharks in craypots reduces the catchability of J. edwardsii, potentially up to $75 \%$ (Hansen 2011). As a result of their unwanted presence, C. laticeps are routinely killed and discarded rather than being released alive (Frusher \& Gibson 1998, Ford 2001, Hansen 2011). Given this potential interaction with $J$. edwardsii, fisheries may influence the trophic ecology of C. laticeps, and fishery-caught specimens may bias the interpretation of diet data.

The objective of this study was to investigate the trophic ecology of Cephaloscyllium laticeps and relate it to fishery interactions. The specific aims were to (1) describe the overall dietary composition of C. laticeps, (2) test for dietary differences between regions of Tasmania, and (3) identify any influence of fishing method (gillnet and craypot) on C. laticeps diet.

\section{MATERIALS AND METHODS}

\section{Study areas and sampling procedures}

Stomach contents of Cephaloscyllium laticeps were collected from 4 regions around Tasmania, Australia: the east coast, the northwest, the southwest and central regions (Fig. 1). Sharks were caught as bycatch from craypot and gillnet fisheries between June 2002 and November 2004. Craypots were baited with either jack mackerel Trachurus declivis and/or barracouta Thyrsites atun. Bait that appeared to be recently ingested (i.e. with no signs of digestion), or that had obviously been cut with a knife, was excluded from the analyses due to the likelihood that it was scavenged from the pots. Fishing method and region were recorded for each shark. Stomach samples were obtained by excising the stomachs onboard the vessel, recording prey that could be easily identified, and storing hard-to-identify prey in $70 \%$ ethanol until further processing in the laboratory. Each prey item was identified to the lowest taxonomic level possible and counted.

\section{Data analysis}

To describe Cephaloscyllium laticeps diet, the percentage frequency of occurrence (\%FO) and percentage of numerical importance $(\% \mathrm{~N})$ metrics were determined for each prey, where $\% \mathrm{FO}$ and $\% \mathrm{~N}$ are 


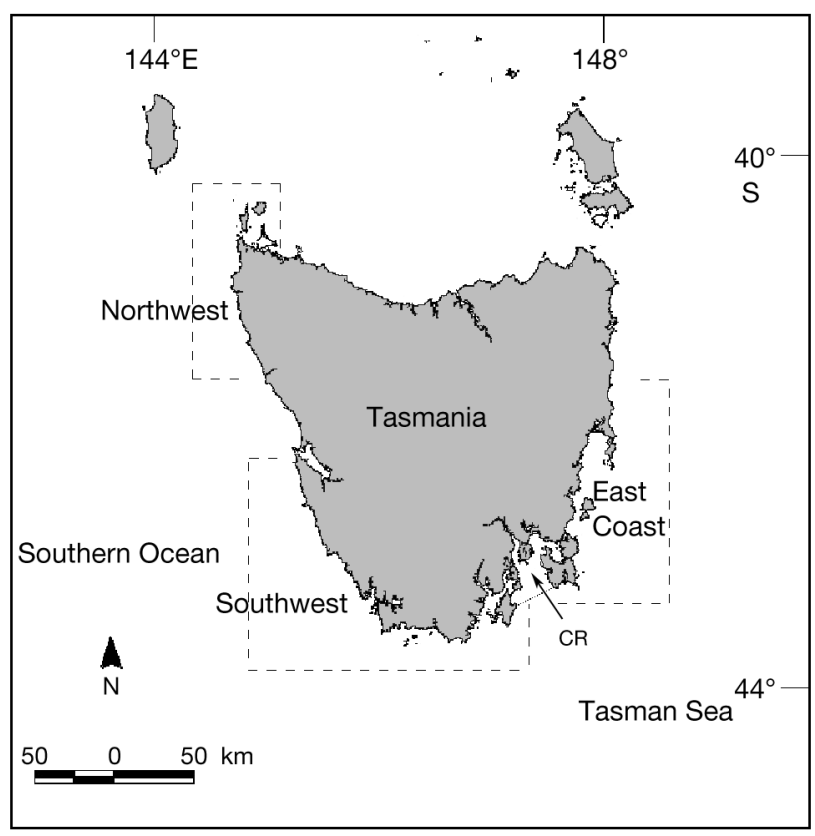

Fig. 1. Sampling regions for Cephaloscyllium laticeps around Tasmania: central region (CR), east coast, northwest, and southwest

the proportion of stomachs in which a particular prey category was found and the proportion of the total number of items belonging to a given prey category, respectively (Hyslop 1980, Baker et al. 2013).

To determine whether the number of stomachs collected was adequate to describe the diet of Cephaloscyllium laticeps in each of the 4 regions, cumulative prey curves were generated, where the cumulative number of prey taxa was plotted against the number of stomachs examined. The curves presented are the average of 999 curves, each based on a separate randomization. An asymptotic curve indicates that sufficient samples were collected to represent the diet of each group. A curve was considered to reach an asymptote if at least 10 previous values of the total number of prey were within 0.5 of the final value. Separate curves were generated for the broad taxonomic group level (groups considered: crustaceans, fish, cephalopods, other molluscs, worms, and miscellaneous (all other organisms)) and for the species level.

Univariate generalized linear models (GLMs) were used to identify the effects of region, fishing method, and the interaction between these 2 factors on the abundance of each of the main prey groups (teleosts, Jasus edwardsii, hermit crabs (mainly Strigopagurus strigimanus), all other crabs, squid (mainly Loliginidae), octopus (all species grouped), and other molluscs (gastropods and bivalves)) on Cephaloscyllium laticeps diet (Warton et al. 2012). Each individual shark stomach was considered a replicate, and empty stomachs were not considered in this analysis. A Poisson distribution with a log-link function was used, as recommended for ecological count data (Crawley 1993, Zuur et al. 2007, 2010, O'Hara \& Kotze 2010, Warton et al. 2012). Optimal model selection was carried out based on the backward stepwise procedure, where the model starts by considering all factors and sequentially removes redundant factors (based on Akaike's information criterion (AIC)) until only the influencing factors remain (Zuur et al. 2007). The optimal model therefore contains only the factors that have an important effect on the dependent variable (prey abundance on the diet). After factor selection, a second GLM was refit using only the factors considered as important based on AIC (Zuur et al. 2007). Models were run for each prey category separately. Analyses were carried out in Brodgar v2.7.2 (Highland Statistics; www.brodgar.com).

To further compare dietary composition between sharks caught in the 4 regions, Pianka's index $(O)$ was calculated to test for dietary niche overlap among sharks from the different regions. Before this analysis, prey were grouped into 10 categories: elasmobranchs, teleosts, Jasus edwardsii, hermit crabs, all other crabs, squid, octopus (all species grouped), sea slugs (Pleurobranchidae), shelled molluscs (mainly Pleuroploca australasia), and worms (polychaetes and sipunculids). Niche overlap calculations were made using $\% \mathrm{~N}$ for these 10 prey categories, and the significance of the niche overlap was tested by comparing values with those obtained by randomization of the original matrices (1000 iterations), using the default (RA3) procedure of the ECOSIM 7.41 software (Gotelli \& Entsminger 2011). The degree of overlap is presented on a 0 to 1 scale, where 0 means no overlap and 1 means complete overlap. A 1-way analysis of similarities (ANOSIM) was then computed (based on a similarity matrix based on Bray-Curtis similarity coefficient (Clarke \& Gorley 2001)) to test for differences in dietary composition between regions. For the east region, the only region for which both gillnet and craypots were used, ANOSIM was also computed to test for differences in dietary composition between individuals caught by gillnet and craypot.

\section{RESULTS}

In total, 1059 stomach samples of Cephaloscyllium laticeps were collected, of which $710(67 \%)$ contained prey: 64 from the central region, 133 from the 
east coast, 90 from the northwest, 361 from the southwest, and for 62 the region was not recorded (Table S1 in the Supplement at www.int-res.com/ articles/suppl/m494p241_supp.pdf). Of the 710 samples containing prey, 242 (35\%) were captured by gillnet, 450 (63\%) by craypot, and for $18(2 \%)$ the fishing method was not recorded. For the samples for which fishing method was recorded, the proportions of gillnet to craypot were as follows: central, 100\% gillnet; east coast, $63 \%$ gillnet, 37\% craypot; northwest, $100 \%$ gillnet; southwest, $100 \%$ craypot.

At the species level, the cumulative prey curves for Cephaloscyllium laticeps did not reach asymptotic stabilization for any of the 4 regions, which suggests that the number of stomachs collected was not sufficient to describe the complete range of prey species consumed (Fig. 2). However, curves generated using broad prey groups reached asymptotic stabilization for all sites (Fig. 2).

Although the overall diet of Cephaloscyllium laticeps was diverse, crustaceans and fish were the dom-
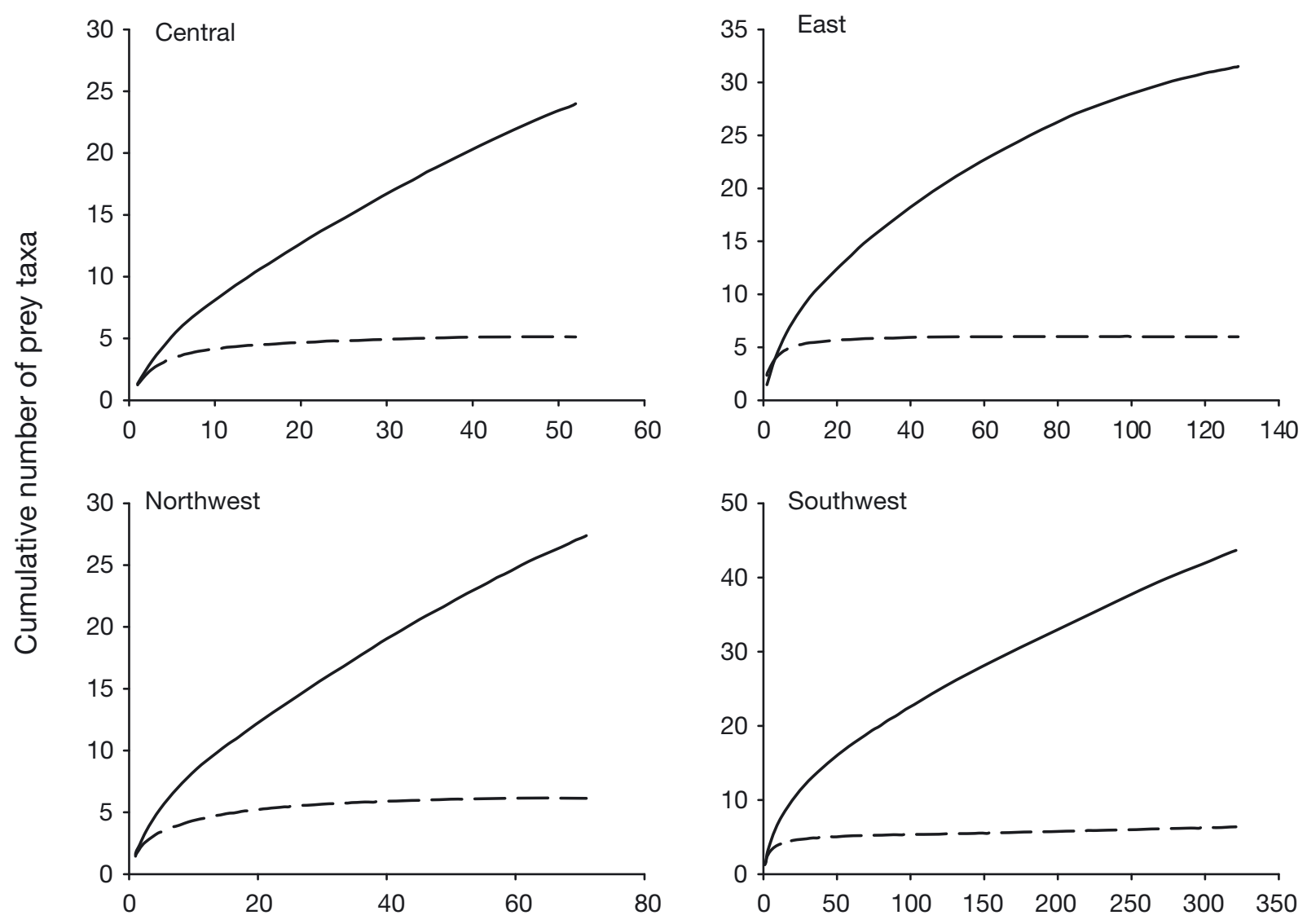

Number of stomachs inant prey, followed by cephalopods (for both \%N and \%FO; Table S1 in the Supplement). At the lowest taxonomic level, the southern rock lobster Jasus edwardsii and the pale octopus Octopus pallidus were the dominant prey in terms of both $\% \mathrm{~N}$ and $\% \mathrm{FO}$ (Table S1). The stridulating hermit crab Strigopagurus strigimanus and the Australian tulip shell Pleuroploca australasia also made important contributions to the overall diet (Table S1). A substantial portion of the diet contained teleosts, but unfortunately a large proportion could not be identified to lower taxonomic levels. Of the teleosts that could be identified, most were slow-swimming benthic species. However, the most common teleosts identified to the lowest taxonomic level were 2 pelagic species, Trachurus declivis and Thyrsites atun (Table S1). Although every effort was made to remove stomach contents recognized as bait from the analyses, caution is needed when determining the importance of these latter species, as it is possible that some of those fish were, in fact, scavenged from the bait used in craypots.

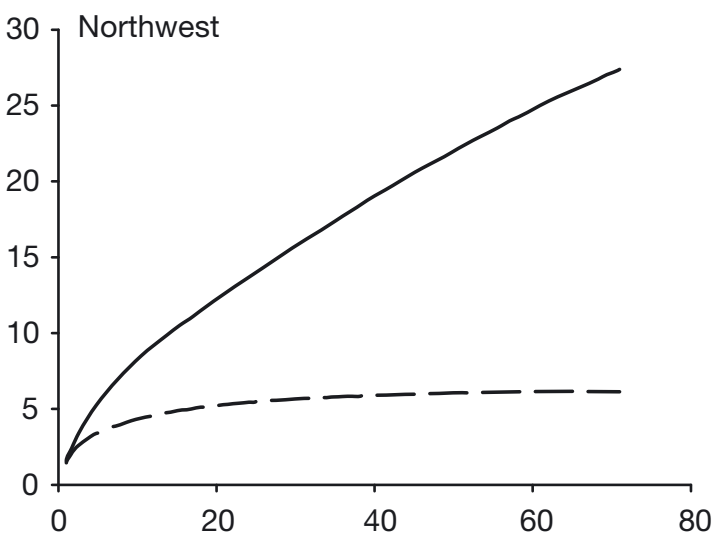

Fig. 2. Randomized cumulative prey curves for Cephaloscyllium laticeps in each of the 4 regions. Solid lines represent curves made at the prey species level and broken lines represent curves made based on broad prey group 


\section{Influence of region and fishing method on Cephaloscyllium laticeps diet}

Neither region nor fishing method was an important factor explaining the abundance of teleosts in Cephaloscyllium laticeps diets. For squid, the optimal model, as selected based on AIC, contained only region as an important factor, while for the remaining prey categories (Jasus edwardsii, octopus, other molluscs, hermit crabs, and other crabs) the AIC factor selection suggested that the models should contain both region and fishing method as explanatory variables. However, for J. edwardsii and hermit crabs, the subsequent GLMs indicated that fishing method was not significant at the $5 \%$ level (Table S2 in the Supplement at www.intres.com/articles/suppl/m494p241_supp.pdf), meaning that this factor could be removed from the optimal models. The interaction between the 2 factors was not identified as significant by any model (Table S2).

Jasus edwardsii were more abundant in the stomachs of sharks captured in the southwest than in sharks captured in the remaining regions, and were less abundant in samples from the northwest than they were in the eastern region (Tables S1 \& S2 in the Supplement). The abundance of $J$. edwardsii in Cephaloscyllium laticeps diets was also higher in the east coast than in the central region (Tables S1 \& S2). The abundance of octopus was higher in the southwest than in the central region and east coast, and there was also an effect of fishing method on the abundance of octopus in C. laticeps diet, as more octopus were found in the diets of sharks captured in nets than in pots (Table S2). Squid were more abundant in diets from sharks from the northwest. Other molluscs (bivalves and gastropods) were less abundant in the diets from the northwest than in the central region and east coast, and there was also an effect of fishing method on the abundance of these molluscs in $C$. laticeps diet, as more of these organisms were found in the stomachs of sharks captured in nets than in sharks captured in pots. Hermit crabs were more abundant in the samples from the east coast than in samples from the remaining regions (Table S2), while other crabs were more abundant in samples from pots than in samples from nets (Table S2). As region was the only, or the most important, factor influencing $C$. laticeps diet for the majority of prey categories, further analyses were run to investigate differences in prey composition between regions.

\section{Dietary overlap}

\author{
Spatial dietary overlap
}

Overall, there was a significant effect of region on the diet composition of Cephaloscyllium laticeps (ANOSIM: $\mathrm{R}=0.071, \mathrm{p}=0.001$ ) (Table 1). Out of the 6 comparisons, 5 displayed moderate to moderatehigh dietary overlap ( $O$ between 0.66 and 0.77 ), although these values were not higher than expected by chance (Table 1). The only exception was between the central and east coast sharks, which had high dietary overlap $(O=0.925)$, significantly higher than expected by chance $(\mathrm{p}=0.003$; Table 1$)$. This high degree of spatial overlap also coincides with no significant difference in dietary composition between sharks from these 2 regions (ANOSIM: $\mathrm{R}=0.011, \mathrm{p}=$ $0.214)$. These relatively high dietary overlap values most likely resulted from the high occurrence and abundance of teleosts in shark diets from all regions and the occurrence of most prey groups in all regions, combined with the low occurrence of some prey in all regions (e.g. elasmobranchs and worms; Table S1). The high occurrence of teleosts and molluscs, in particular Pleuroploca australasia, is the main driver for the high overlap between central and east coast sharks (Table S1).

Despite the relatively high overlap driven by similar teleost consumption, significant differences in diet were evident among most regions (Table 1). Sharks from the central and southwest regions showed the lowest dietary overlap $(O=0.660)$, which was driven by sharks from the southwest consuming much higher proportions of crustaceans, in particular Jasus edwardsii, and very few shelled molluscs compared with central region sharks (Table S1).

Table 1. Analysis of similarities (ANOSIM) and Pianka's index $(O)$ results for regional dietary comparisons of Cephaloscyllium laticeps based on 10 prey categories. pvalues for Pianka's index are the proportion of the randomizations that resulted in an overlap equal to or greater than the empirical (observed) overlap value

\begin{tabular}{|lcccc|}
\hline \multirow{2}{*}{ Regions } & \multicolumn{3}{c}{ ANOSIM } & \multicolumn{2}{c|}{ Pianka's index } \\
& $\mathrm{R} \quad \mathrm{p}$-value & $O$ & $\mathrm{p}$-value \\
& & & & \\
\hline Central vs. east coast & 0.011 & 0.214 & 0.925 & 0.003 \\
Central vs. northwest & 0.047 & 0.008 & 0.726 & 0.076 \\
Central vs. southwest & 0.086 & 0.001 & 0.660 & 0.115 \\
East coast vs. northwest & 0.044 & 0.001 & 0.749 & 0.082 \\
East coast vs. southwest & 0.077 & 0.001 & 0.774 & 0.053 \\
Northwest vs. southwest & 0.076 & 0.001 & 0.743 & 0.094 \\
& & & & \\
\hline
\end{tabular}


Similarly, the importance of shelled molluscs and hermit crabs Strigopagurus strigimanus to east coast sharks, and southwest sharks consuming J. edwardsii in larger proportions, contributed to differences between these 2 regions (Tables $1 \& \mathrm{~S} 1$ ).

Sharks from the northwest showed moderate to moderate-high dietary overlap with sharks from all other regions (Table 1). The high consumption of squid in the northwest was the distinguishing feature of the diets of sharks in this region (Table S1). The higher consumption of Pleuroploca australasia in the central and east coast region, Strigopagurus strigimanus from the east coast, and Jasus edwardsii from the southwest also contributed to differences in diets between sharks from these areas and sharks from the northwest (Tables S1 \& S2).

\section{Gillnet vs. craypot (east coast)}

There was a high and significant amount of dietary overlap $(O=0.918, \mathrm{p}=0.006$ (i.e. only $0.6 \%$ of the randomizations resulted in overlap equal or greater than observed value)) between net- and pot-caught sharks from the east coast. Interestingly, there were also significant differences in diet between these 2 groups (ANOSIM: $\mathrm{R}=0.054, \mathrm{p}=0.002$ ). However, these differences were not driven by a higher proportion (based on \% N) of pot-related species (Jasus edwardsii and octopus) in pot-caught Cephaloscyllium laticeps. Indeed, J. edwardsii made up similar proportions of the diets in nets $(11 \%)$ and pots $(8 \%)$, while the proportion of octopus was slightly higher in net-caught than in pot-caught sharks $(13 \%$ and $8 \%$, respectively). In contrast, squid were more prevalent in pot-caught $(7 \%)$ than in net-caught $(2 \%)$ sharks.

\section{DISCUSSION}

Trophic studies are fundamental components for investigating species ecology and understanding broader ecosystem questions such as food web dynamics, interspecies relationships, and ecosystem function. However, the influence of fisheries on the trophic ecology of fishery-related species is often overlooked. This study showed that fisheries can have an effect on a species' diet (or interpretation of diet data) and foraging behaviour. Indeed, although differences in Cephaloscyllium laticeps diet were mostly driven by region, fishing method also played an important part in driving these differences. Most of the main prey types were present in stomachs of sharks caught in all regions and by both fishing methods, suggesting that fisheries do not influence the prey $C$. laticeps targets at a broad taxonomic level, but do influence the prominence of some prey in their diets. For example, dietary differences related to the fishing method used could be a result of the sharks opportunistically foraging on prey that are easier to catch once inside the craypots, e.g. crabs were found in greater abundance in the diet of potcaught sharks, coinciding with crabs being a significant component of craypot bycatch (Frusher \& Gibson 1998). Also, the fact that C. laticeps are commonly caught in craypots suggests that the southern rock lobster fishery influences their foraging behaviour, by providing food to scavenge (bait) and trapping prey (crabs, lobsters), therefore promoting trap raiding. It is thus important to keep in mind that the fishing method used can have an effect on both predator behaviour and interpretation of dietary data, and should be taken into account when extrapolating results to the overall population level.

The greater abundance of octopus in the diet of Cephaloscyllium laticeps caught with gillnets was surprising, as octopus are associated with craypots, both as a common bycatch and because some species are predators of the lobsters captured in craypots (Frusher \& Gibson 1998, Brock et al. 2003, Hunter et al. 2005, Harrington et al. 2006, Hansen 2011). The slightly greater occurrence of octopus in gillnetcaught $C$. laticeps suggests that in-pot predation on octopus is not common.

Given the common occurrence of Cephaloscyllium laticeps in craypots, another surprising result was that there was no effect of fishing method on the prevalence of Jasus edwardsii in C. laticeps diet, as $J$. edwardsii was found in the diets of C. laticeps caught in both nets and pots. However, the consumption of $J$. edwardsii was much higher in the southwest, where only pots were used. As region was identified by the GLM as the main factor affecting $J$. edwardsii abundance in C. laticeps diet, we have to assume that some factors in the southwest favour predation of $J$. edwardsii, e.g. higher abundance of this prey. Note, however, that although not significant at the $5 \%$ level, the secondary GLM model suggested that the abundance of $J$. edwardsii was higher in the diet of pot-caught sharks (Table S2), meaning that fishing method could have some influence on J. edwardsii importance to C laticeps diet, e.g. $J$. edwardsii trapped in craypots become easy prey.

Although care was taken to remove the 2 species used as bait (Trachurus declivis and Thyrsites atun) from the analyses, potting could have some influence 
on the diet of Cephaloscyllium laticeps by increasing the importance of bait species. However, even for the pot-caught sharks, the importance of these prey was low (Table S1), and T. declivis is still a prominent prey in the diet of C. laticeps off Tasmania (e.g. in net-caught sharks in this study), Victoria, and New South Wales (Australia) (Bulman et al. 2001). The introduction of bait and discards by fisheries into the environment has been shown to influence the trophic ecology of other species (e.g. Olaso et al. 1998, Waddington et al. 2008), with the potential for further consequences to ecosystem function (Waddington et al. 2008). For example, bait is an important component of lobster diets in numerous regions of the world (see Waddington et al. 2008); and the occurrence of large amounts of discarded bait from the western rock lobster Panulirus cygnus fishery (Western Australia) in the diet of tiger sharks Galeocerdo cuvier suggests that the seasonal abundance of this food source may influence the foraging behaviour of this shark species (Simpfendorfer et al. 2001). In Tasmania, the introduction of bait through the craypot fishery could have a similar influence over the local trophic ecology.

The relationship between the key species associated with the craypot fishery, Jasus edwardsii, Cephaloscyllium laticeps, octopus and humans, is interesting. Octopus, mainly Octopus maorum, are within-craypot predators of $J$. edwardsii (Brock et al. 2003, Hunter et al. 2005, Harrington et al. 2006, Hansen 2011), and may have a greater negative impact on the fishery than C. laticeps (Hansen 2011). These relationships are further entwined in Tasmania because a number of octopus species, in particular $O$. maorum and $O$. pallidus, are also targeted fishery species.

Overall, detailed investigations on how fishing method influences interpretation of stomach content data are lacking. For example, regurgitation during the fishing process can lead to information loss and to the underestimation of prey importance (e.g. Sutton et al. 2004, Vignon \& Dierking 2011). This can be particularly important in dietary analysis of elasmobranchs, as many species are able to evert their stomachs with no apparent ill effects (Simpfendorfer et al. 2001, Barnett et al. 2010b). Despite a few studies suggesting that fish species can feed while caught in fishing gear, or feed from the fishing gear before being caught (Baremore et al. 2008, Barnett et al. 2010a), we could only find 1 publication addressing this issue in detail. In that study, Ibáñez et al. (2008) showed that in-net feeding by the jumbo squid Dosidicus gigas artificially inflated the importance of some prey and the prevalence of cannibalism. Thus, not considering the fishing method in dietary analyses can lead to under- or overestimation of certain prey, and to misleading results regarding the trophic ecology of the study species.

In conclusion, Cephaloscyllium laticeps consumed the same broad prey types in all 4 regions, but the relative amounts of some of the prey varied among regions. Fishing method also influenced the abundance of certain prey in C. laticeps diet. Yet, the influence of craypots on pot-related species such as Jasus edwardsii and octopus was not as prevalent as expected. The common occurrence of $C$. laticeps as a prominent bycatch species and its high consumption of targeted fishery species, in particular $J$. edwardsii and octopus, but also squid and Trachurus declivis, indicates that $C$. laticeps has a strong association with fisheries.

Acknowledgements. The authors thank S. Grove for his aid with the identification of invertebrates, and N. Perryman for providing samples. All research was conducted under the approval of the University of Tasmania Animal Care and Ethics Committee (A0007219).

\section{LITERATURE CITED}

Awruch CA, Frusher SD, Stevens JD, Barnett A (2012) Movement patterns of the draughtboard shark Cephaloscyllium laticeps (Scyliorhinidae) determined by passive tracking and conventional tagging. J Fish Biol 80:1417-1435

Baker R, Buckland A, Sheaves M (2013) Fish gut content analysis: robust measures of diet composition. Fish Fish, doi:10.1111/faf.12026

Baremore IE, Murie DJ, Carlson JK (2008) Prey selection by the Atlantic angel shark Squatina dumeril in the northeastern Gulf of Mexico. Bull Mar Sci 82:297-313

Barnett A, Semmens JM (2012) Sequential movement into coastal habitats and high spatial overlap of predator and prey suggest high predation pressure in protected areas. Oikos 121:882-890

> Barnett A, Abrantes K, Stevens JD, Yick J, Frusher SD, Semmens JM (2010a) Predator-prey relationships and foraging ecology of a marine apex predator with a wide temperate distribution. Mar Ecol Prog Ser 416:189-200

Barnett A, Redd KS, Frusher SD, Stevens JD, Semmens JM (2010b) Non-lethal method to obtain stomach samples from a large marine predator and the use of DNA analysis to improve dietary information. J Exp Mar Biol Ecol 393:188-192

Bethea DM, Buckel JA, Carlson JK (2004) Foraging ecology of the early life stages of four sympatric shark species. Mar Ecol Prog Ser 268:245-264

Brock D, Saunders T, Ward TM (2003) Development and assessment of methods to reduce the predation of 'pot caught' southern rock lobster (Jasus edwardsii) by Maori octopus (Octopus maorum). Aquatic Sciences Publication No. RD03/0063. South Australian Research and Development Institute (SARDI), Adelaide 
Bulman C, Althaus F, He X, Bax NJ, Williams A (2001) Diets and trophic guilds of demersal fishes of the south-eastern Australian shelf. Aust J Mar Freshw Res 52:537-548

Clarke KR, Gorley RN (2001) Primer v5. PRIMER-E, Plymouth

Crawley MJ (1993) GLIM for ecologists. Blackwell, Oxford

Estes JA, Terborgh J, Brashares JS, Power ME and others (2011) Trophic downgrading of planet Earth. Science 333:301-306

Ford W (2001) Assessing the ecological sustainability of the Tasmanian rock lobster fishery, a report prepared for Environment Australia. Department of Primary Industries, Water and Environment (DPIWE), Hobart

Frusher S, Gibson IJ (1998) Bycatch in the Tasmanian rock lobster fishery. In: Buxton C, Eayrs S (eds) Proc Australian Society for Fish Biology workshop on establishing meaningful targets for bycatch reduction in Australian fisheries. Australian Society for Fish Biology, Hobart, p 73-81

Gardner C, Hartmann K, Hobday D (2011) Fishery assessment report: Tasmanian rock lobster fishery 2009/2010. Tasmanian Aquaculture and Fisheries Institute (TAFI), Hobart

Gonzalez-Zevallos D, Yorio P (2006) Seabird use of discards and incidental captures at the Argentine hake trawl fishery in the Golfo San Jorge, Argentina. Mar Ecol Prog Ser 316:175-183

Gotelli NJ, Entsminger GL (2011) EcoSim: null models software for ecology. Version 7. Acquired Intelligence Inc. and Kesey-Bear, Jericho, VT. http://garyentsminger. com/ecosim/

Hansen W (2011) The impact of ferrite magnets on elasmobranch bycatch in the Tasmanian southern rock lobster fishery. Honours dissertation, Australian Maritime College, Launceston

> Harrington JJ, Semmens JM, Gardner C, Frusher SD (2006) Predation of trap-caught southern rock lobsters, Jasus edwardsii (Hutton, 1875), in Tasmanian waters by the Maori octopus, Octopus maorum (Hutton, 1880): spatial and temporal trends. Fish Res 77:10-16

> Heithaus MR, Frid A, Wirsing AJ, Worm B (2008) Predicting ecological consequences of marine top predator declines. Trends Ecol Evol 23:202-210

Hill BJ, Wassenberg TJ (1990) Fate of discards from prawn trawlers in Torres Strait. Aust J Mar Freshw Res 41:53-64

> Hunter CM, Haddon M, Sainsbury KJ (2005) Use of fisherydependent data for the evaluation of depensation: case study involving the predation of rock lobster (Jasus edwardsii) by octopus (Octopus maorum). N Z J Mar Freshw Res 39:455-469

- Hyslop EJ (1980) Stomach contents analysis: a review of methods and their application. J Fish Biol 17:411-429

> Ibáñez CM, Arancibia H, Cubillos LA (2008) Biases in determining the diet of jumbo squid Dosidicus gigas ( $\mathrm{D}^{\prime}$ Orbigny 1835) (Cephalopoda: Ommastrephidae) off southern-central Chile $\left(34^{\circ} \mathrm{S}-40^{\circ} \mathrm{S}\right)$. Helgol Mar Res 62:331-338

Koen Alonso M, Crespo EA, Garcia NA, Pedraza SN, Mariotti PA, Mora NJ (2002) Fishery and ontogenetic driven changes in the diet of the spiny dogfish (Squalus acanthias), in Patagonian waters, Argentina. Environ Biol Fishes 63:193-202

Last PR, Stevens JD (2009) Sharks and rays of Australia, 2nd edn. CSIRO Publishing, Collingwood
Lucifora LO, Garcia VB, Escalante AH (2009) How can the feeding habits of the sand tiger shark influence the success of conservation programs? Anim Conserv 12: 291-301

> Lunneryd SG, Fjalling A, Westerberg H (2003) A large-mesh salmon trap: a way of mitigating seal impact on a coastal fishery. ICES J Mar Sci 60:1194-1199

- O'Hara RB, Kotze DJ (2010) Do not log-transform count data. Methods Ecol Evol 1:118-122

> Okes NC, Hockey PAR, Pichegru L, van der Lingen CD, Crawford RJM, Gremillet D (2009) Competition for shifting resources in the southern Benguela upwelling: seabirds versus purse-seine fisheries. Biol Conserv 142: 2361-2368

- Olaso I, Velasco F, Perez N (1998) Importance of discarded blue whiting (Micromesistius poutassou) in the diet of lesser spotted dogfish (Scyliorhinus canicula) in the Cantabrian Sea. ICES J Mar Sci 55:331-341

> Pichegru L, Ryan PG, Le Bohec C, van der Lingen CD and others (2009) Overlap between vulnerable top predators and fisheries in the Benguela upwelling system: implications for marine protected areas. Mar Ecol Prog Ser 391: 199-208

Pichegru L, Gremillet D, Crawford RJM, Ryan PG (2010) Marine no-take zone rapidly benefits endangered penguin. Biol Lett 6:498-501

> Ritchie EG, Johnson CN (2009) Predator interactions, mesopredator release and biodiversity conservation. Ecol Lett 12:982-998

Simpfendorfer CA, Goodreid AB, McAuley RB (2001) Size, sex and geographic variation in the diet of the tiger shark, Galeocerdo cuvier, from Western Australian waters. Environ Biol Fishes 61:37-46

Sutton TM, Cyterski MJ, Ney JJ, Duval MC (2004) Determination of factors influencing stomach content retention by striped bass captured using gillnets. J Fish Biol 64: 903-910

- Varjopuro R (2011) Co-existence of seals and fisheries? Adaptation of a coastal fishery for recovery of the Baltic grey seal. Mar Policy 35:450-456

Vignon M, Dierking J (2011) Prey regurgitation and stomach vacuity among groupers and snappers. Environ Biol Fishes 90:361-366

Waddington KI, Bellchambers LM, Vanderklift MA, Walker DI (2008) Western rock lobsters (Panulirus cygnus) in Western Australian deep coastal ecosystems (35-60 m) are more carnivorous than those in shallow coastal ecosystems. Estuar Coast Shelf Sci 79:114-120

Walker TI, Hudson RJ, Gason AS (2005) Catch evaluation of target, by-product, and by-catch species taken by gillnets and longlines in the shark fishery of south-eastern Australia. J Northwest Atl Fish Sci 35:505-530

> Warton DI, Wright ST, Wang Y (2012) Distance-based multivariate analyses confound location and dispersion effects. Methods Ecol Evol 3:89-101

> Yick JL, Barnett A, Tracey SR (2012) The trophic ecology of two abundant mesopredators in south-east coastal waters of Tasmania, Australia. Mar Biol 159:1183-1196

Zuur AF, Ieno EN, Smith GM (2007) Analyzing ecological data. Springer, New York, NY

> Zuur AF, Ieno EN, Elphick CS (2010) A protocol for data exploration to avoid common statistical problems. Methods Ecol Evol 1:3-14

Submitted: March 18, 2013; Accepted: September 30, 2013 Proofs received from author(s): December 1, 2013 